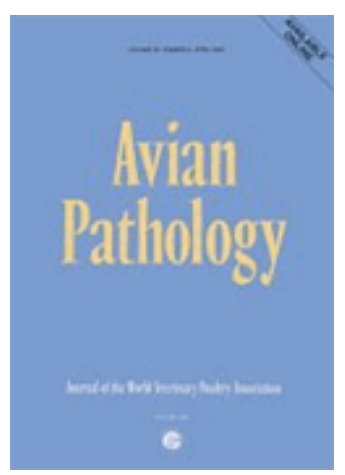

\title{
Necrotic enteritis in broilers: an update on the pathogenesis
}

\begin{tabular}{|r|l|}
\hline Journal: & Avian Pathology \\
\hline Manuscript ID: & CAVP-2011-0025.R1 \\
\hline Manuscript Type: & Review \\
\hline Date Submitted by the \\
Author: & 14-Mar-2011 \\
\hline Complete List of Authors: & $\begin{array}{l}\text { Timbermont, Leen; Ghent University, Pathology, Bacteriology and } \\
\text { Avian Diseases } \\
\text { Haesebrouck, Freddy; Ghent University, Pathology, Bacteriology } \\
\text { and Avian Diseases } \\
\text { Ducatelle, Richard; Ghent University, Pathology, Bacteriology and } \\
\text { Avian Diseases } \\
\text { Van Immerseel, Filip; Ghent University, Pathology, Bacteriology and } \\
\text { Avian Diseases }\end{array}$ \\
\hline Keywords: & \begin{tabular}{l} 
clostridium perfringens, necrotic enteritis, pathogenesis, broilers \\
\hline
\end{tabular} \\
\hline
\end{tabular}

\section{SCHOLARONE"}

Manuscripts 


\section{Review Article}

\section{Cavp-2011-0025.R1}

Necrotic enteritis in broilers: an updated review on the pathogenesis

\section{Timbermont ${ }^{*}$, F. Haesebrouck, R. Ducatelle, F. Van Immerseel}

Department of Pathology, Bacteriology and Poultry Diseases, Research Group Veterinary Public Health and Zoonoses, Faculty of Veterinary Medicine, Ghent University, Salisburylaan 133, B-9820 Merelbeke, Belgium.

Short title: Pathogenesis of broiler necrotic enteritis

Received: 14 March 2011

\footnotetext{
*To whom correspondence should be addressed: Tel: + 329264 7448. Fax: + 3292647494 E-mail: leen.timbermont@ugent.be
} 


\section{Abstract}

Clostridium perfringens-induced necrotic enteritis and related subclinical disease have become economically significant problems for the broiler industry. Fortunately, scientific interest in this topic has grown: new $C$. perfringens virulence factors have been discovered and new insight gained about the pathogenesis of necrotic enteritis. It has been shown that alpha toxin, for a long time thought to be the key virulence factor, is not essential for the development of the disease. Moreover, it is now clearly established that only certain C. perfringens strains are capable of inducing necrotic enteritis under specific conditions that predispose to the disease and they constitute only a minority in the intestinal tract of healthy chickens. A novel pore-forming toxin, NetB, has been identified in these virulent avian C. perfringens strains. Using a gene knockout mutant, it has been shown that NetB is a critical virulence factor in the pathogenesis of necrotic enteritis in broilers.

In addition to toxin production, other factors have been described that contribute to the ability of certain C. perfringens strains to cause necrotic enteritis in broilers. It has been suggested that proteolytic enzymes play an important role in the initial stages of necrotic enteritis since the villi are first affected at the level of the basement membrane and the lateral domain of the enterocytes. In field outbreaks of necrotic enteritis, a single clone of C. perfringens is dominant in intestines of all affected birds, as opposed to the mixture of different $C$. perfringens strains that can be isolated from healthy bird intestines. It has been proposed that bacteriocin production is responsible for the dominance of a single strain in necrotic enteritis cases. Furthermore, it has been shown that virulent strains are more able to adhere to extracellular matrix molecules than non-virulent strains. The current knowledge on the pathogenesis of the disease has been summarized in this short review. 


\section{Introduction}

Enteric diseases are an important concern to the poultry industry because of production losses, increased mortality, reduced welfare of birds and increased risk of contamination of poultry products for human consumption. Necrotic enteritis was first described by Parish (1961). It is a widespread disease in broilers imposing a significant economic burden on the poultry industry worldwide. The total global economic loss as a consequence of necrotic enteritis outbreaks in broiler farms is estimated to be over 2 billion dollars annually (Van der Sluis, 2000a,b). The causative agent of necrotic enteritis is Clostridium perfringens, a Gram-positive spore-forming anaerobe.

Growth-promoting antibiotics have been banned from animal feed in the European Union and, worldwide, the use of antimicrobial growth promoters is being reduced because of concern for the spread of antimicrobial resistance. This has contributed to the higher prevalence of economically important diseases such as necrotic enteritis (Van Immerseel et al., 2009).

Clinical signs and lesions. Necrotic enteritis usually occurs in broiler chickens at about 4 weeks after hatching and is found in all poultry-growing areas of the world (Long, 1973; Dahiya et al., 2006). It may present as acute clinical disease or be a subclinical condition.

Clinical necrotic enteritis. The classical acute clinical form of the disease is characterized by a sudden increase in flock mortality, often without premonitory signs, although wet litter is sometimes an early indicator of disease. The course is often peracute, with death in 1 to 
2 hours. Mortality rates may sometimes rise up to 50\% (Helmboldt \& Bryant, 1971;

Wijewanta \& Senevirtna, 1971; Kohler, 1973; Riddell \& Kong, 1992).

Subclinical form of Clostridium perfringens infection. In the past few years, a subclinical form has become more prevalent. In this form of necrotic enteritis, no overt clinical signs are present and usually there is no peak mortality. Chronic intestinal mucosal damage leads to production losses due to poor digestion and absorption, reduced weight gain and increased feed-conversion ratio (Elwinger et al., 1992; Kaldhusdal et al., 2001). During subclinical infection, the intestinal damage can allow the bacteria to reach the bile duct and portal blood stream. Colonization of the liver by high numbers of $C$. perfringens results in cholangiohepatitis. Diseased livers are enlarged and have a pale appearance with red or white foci (Onderka et al., 1990; Løvland \& Kaldhusdal, 1999; Sasaki et al., 2000). Liver lesions are found during meat inspection at slaughter, often without any sign of clinical disease in the flock. This increases the number of condemnations at processing. Taken together, there is a general consensus that, although clinical outbreaks of necrotic enteritis may cause high levels of mortality, the subclinical form of the disease is more important than the clinical form because it may persist in broiler flocks without overt clinical manifestations. Since the disease is undetected and birds remain untreated, subclinical necrosis causes the greatest economic losses in the poultry production industry (Kaldhusdal \& Hofshagen, 1992; Dahiya et al., 2006).

Intestinal pathology. Gross lesions are usually restricted to the small intestine, but lesions can also occur in other organs, such as liver and kidney. Upon necropsy, the duodenum, jejunum and ileum are usually thin walled and filled with gas. Clinical necrotic enteritis is characterized by confluent mucosal necrosis of large parts of the small intestine, covered with 
a yellow-brown or bile-stained pseudomembrane (Figure 1A) (Helmbold \& Bryant, 1971; Long et al., 1974; Broussard et al., 1986; Olkowski et al., 2006). Typical subclinical cases have ulcers in the form of a depression in the mucosal surface, with discolored, amorphous material adhering to the mucosal surface (Figure 1B) (Kaldhusdal \& Hofshagen, 1992).

Microscopic examination of early stages of necrotic enteritis show strong inflammatory reactions to $C$. perfringens. The lamina propria is hyperaemic and infiltrated with numerous inflammatory cells, mainly heterophilic granulocytes. Most significant early changes are seen at the interface of the basal domain of enterocytes and lamina propria. These areas are extensively oedematous, allowing for the substantial disturbance of the structural integrity between the lamina propria and the enterocytes (Olkowski et al., 2006). Microscopic examination of later stages of necrotic enteritis lesions show diffuse and severe coagulative necrosis of the mucosa, involving the luminal third to half of the mucosa. In these areas necrosis of enterocytes is apparent on the villi. A clear line of demarcation between necrotic and viable tissue and an accumulation of heterophilic granulocytes at the junction is seen. If present, the pseudomembrane consists of masses of tissue fragments, necrotic cells, cell debris, and numerous bacterial colonies suspended in mucus. Congestion of blood vessels is detected in the lamina propria and submucosa. Large, Gram-positive rods are associated with areas of necrosis but do not invade the epithelium or are not found to be attached to the viable mucosal epithelial cells, despite their massive presence on the tissue debris in the lumen (Helmboldt and Bryant, 1971; Long et al., 1974; Al-Sheikhly and Al-Saieg, 1980; Broussard et al., 1986; Olkowski et al., 2006).

Predisposing factors. Nutrition. The key risk factor for the development of necrotic enteritis is an intestinal environment that favours growth of $C$. perfringens. The nature of the diet is an important non-bacterial factor that influences the incidence of necrotic enteritis. Diets with 
high levels of indigestible, water-soluble non-starch polysaccharides predispose to necrotic enteritis. Thus, wheat, rye, oats and barley are risk factors for necrotic enteritis, whereas maize is not (Branton et al., 1987; Hofshagen \& Kaldhusdal, 1992; Kaldhusdal \& Hofshagen, 1992; Kaldhusdal \& Skjerve, 1996; Riddell \& Kong, 1992; Craven, 2000; Jia et al., 2009). Some of these effects may be related to differences in digesta viscosity, decreased nutrient digestibility and prolonged intestinal transit time (Choct et al., 1996). High dietary concentrations of animal protein, such as fishmeal, have also been reported to increase the incidence of necrotic enteritis (Truscott \& Al-Sheikhly, 1977; Drew et al., 2004;

Gholamiandehkordi et al., 2007). In general, protein-rich diets containing relatively high concentrations of poorly digestible proteins lead to high concentrations of protein in the gastrointestinal tract and thus act as substrates for the bacteria.

The dietary fat source may also have an effect on the $C$. perfringens population. Animal fat increases $C$. perfringens counts compared to vegetable oil (Knarreborg et al., 2002). Even the physical form of the feed may influence the incidence of necrotic enteritis. Feed containing some large-sized and many small-sized particles predispose more to necrotic enteritis than feed containing particles uniform in size (Branton et al., 1987; Engberg et al., 2002).

Stress. Apart from the feed, any factor that causes stress in broiler chickens could predispose them to necrotic enteritis because it could alter the intestinal environment in such a way that the risk of induction of necrotic enteritis is elevated (McDevitt et al., 2006). Programmed alterations in the feeding regime (moving from starter diets to grower diets), are frequently associated with necrotic enteritis. Furthermore, immunosuppressive agents such as chick anaemia virus, Gumboro disease or Marek's disease, reduce resistance to gut infections and may increase the severity of disease. Also increases in stocking density predispose to necrotic 
enteritis (McDevitt et al., 2006). However, the latter is restricted in the European Union by legislation to $33 \mathrm{~kg} / \mathrm{m}^{2}$ and can be, under certain conditions, raised to $42 \mathrm{~kg} / \mathrm{m}^{2}$ (directive 2007/43/EG).

Coccidiosis. The best-known predisposing factor for necrotic enteritis is mucosal damage caused by coccidial pathogens (Williams, 2005). Coccidiosis is often seen to precede or occur concurrently with field outbreaks of necrotic enteritis (Long, 1973; Broussard et al., 1986; Gazdzinski \& Julian, 1992; Porter, 1998). Moreover, it has been shown in experimental infection studies that $C$. perfringens and Eimeria spp. act synergistically in inducing necrotic enteritis lesions. Co-infection with C. perfringens and Eimeria oocysts or an overdose of commercial coccidiosis vaccines containing attenuated Eimeria strains result in more animals with lesions or in higher mortality rates compared with birds receiving only Eimeria or only C. perfringens (Al-Sheikhly \& Al-Saieg, 1980; Shane et al., 1985; Baba et al., 1997; Gholamiandehkordi et al., 2007; Park et al., 2008; Pedersen et al., 2008). Eimeria parasites colonize the small intestine and kill epithelial cells as a consequence of the intracellular stages of their life cycle (Williams, 2005). Plasma proteins leak into the gut lumen through the resulting gaps in the epithelial lining of the intestinal lumen, and these can be used as growthsubstrate by C. perfringens strains (Van Immerseel et al., 2004). Moreover, coccidial infection induces a T-cell mediated inflammatory response that enhances intestinal mucogenesis. This enhanced mucin production provides a growth advantage to $C$. perfringens due to its ability to use mucus as a substrate (Collier et al., 2008).

Presence of poultry pathogenic strains. The intestine of birds suffering from necrotic enteritis contains large numbers of $C$. perfringens organisms, up to $10^{6}-10^{8} \mathrm{cfu} / \mathrm{g}$ of the intestinal contents, whereas in healthy broilers, counts from $0-10^{5} \mathrm{cfu} / \mathrm{g}$ of the intestinal 
contents are normal (Long et al., 1974; Baba et al., 1997; Si et al., 2007). However, the presence of $C$. perfringens in the intestinal tract of broiler chickens, even at high numbers, is not sufficient to produce necrotic enteritis (Long \& Truscott, 1976; Cowen et al.; 1987, Kaldhusdal et al., 1999; Craven, 2000; Pedersen et al., 2003; Nauerby et al., 2003). Therefore, $C$. perfringens cell counts alone have not been directly associated with necrotic enteritis. Indeed, not all $C$. perfringens strains are able to induce necrotic enteritis; they need to possess host specific virulence factors in order to be pathogenic for poultry.

It is pertinent to note that $C$. perfringens is auxotrophic for 13 amino acids (Shimizu et al., 2002; Myers et al., 2006). An increase in available nutrients would thus allow C. perfringens to proliferate extensively, leading to increased intestinal toxin levels. It can thus be speculated that when the conditions for inducing lesions are present, a higher number of bacteria might result in more severe lesions but only when poultry pathogenic strains are present. Predisposing factors are thus important but it is essential that a poultry pathogenic strain is present to induce disease.

Bacteriocins. Bacteriocins may have an important role in the pathogenesis of necrotic enteritis. Genetic characterization by PFGE or amplified fragment length polymorphism (AFLP) has revealed that in healthy flocks, different genotypes of $C$. perfringens type A can be found, even within individual birds and within the same gut segment. In contrast, isolates from a flock with necrotic enteritis are generally clonal within one flock, regardless of the animal or the organ of isolation (Engström et al., 2003; Nauerby et al., 2003;

Gholamiandehkordi et al., 2006). These results were confirmed by multilocus sequence typing analysis (MLST) (Chalmers et al., 2008). After natural recovery or treatment, birds again start carrying multiple genetic types (Nauerby et al., 2003). The fact that this single strain dominance has been described in several studies indicates that it is an essential step in 
the pathogenesis of necrotic enteritis. Moreover, this dominance of one virulent C. perfringens isolate could be reproduced in an experimental infection model after administration of a combined inoculum comprising different necrotic enteritis strains or a combination of virulent and avirulent $C$. perfringens strains (Barbara et al., 2008). Finally, the secretion of factors inhibiting growth of other $C$. perfringens strains is shown to be more prevalent in outbreak strains than in normal microbiota strains in vitro (Barbara et al., 2008; Timbermont et al., 2009b). Proteinaceous toxic compounds produced by bacteria that generally inhibit the growth of closely related strains are called bacteriocins (Jack et al., 1995). Taken together, these results suggest that this is a trait associated with virulence. Although there is no information on in vivo bacteriocin production by $C$. perfringens, production of bacteriocins by a virulent strain in the gut would allow this strain to displace the C. perfringens strains present. Inhibiting the growth of other $C$. perfringens strains in the gut can also be important as part of the competition for nutrients.

Collagenolytic enzymes. Olkowski et al. $(2006,2008)$ suggested that the initial pathological changes are due to the activity of collagenolytic enzymes. It was shown that damage to the villi initially occurs at the level of the basement membrane and lateral domain of the enterocytes, spreading throughout the lamina propria, while epithelial damage occurs later in the process. The nature of the morphological changes indicates that the initiation of the pathological process leading to necrotic enteritis involves proteolytic factors affecting the extracellular matrix and cellular junctions. Indeed, in broilers undergoing necrotic enteritis, the extracellular matrix is disorganized and can even be completely absent. It was shown that C. perfringens strains isolated from field cases of necrotic enteritis secrete several potent collagenolytic enzymes and that broilers challenged with $C$. perfringens show elevated levels of several collagenolytic enzymes in the intestinal tissue in comparison to controls. It was 
thus suggested that the pathology may be the result of bacterial collagenases, whose action is enhanced when mucosal damage (e.g. induced by coccidia) is present, or of host matrix metalloproteinases that are activated by the host-pathogen interaction (Olkowski et al., 2008).

Toxin production. For a long time, alpha toxin was proposed to be the main virulence factor for necrotic enteritis in poultry, although C. perfringens outbreak strains as well as normal broiler microbiota isolates are type A and thus express alpha toxin (Nauerby et al., 2003; Gholamiandehkordi et al., 2006). Moreover, no apparent difference in the levels of alpha toxin was found when the alpha toxin production in vitro was compared between strains associated with necrotic enteritis and isolates derived from the microbiota of normal broilers (Gholamiandehkordi et al., 2006). Yet another study found that the intestinal level of alpha toxin was not correlated with disease lesion scores (Wilkie et al., 2006). Finally, an alpha toxin null mutant, constructed from a virulent chicken isolate, was equally able to cause necrotic lesions in broiler chickens compared to the wild-type strain (Keyburn et al., 2006). Another observation that argues strongly against the role of alpha toxin in necrotic enteritis is the massive heterophil, lymphocyte, and plasma cell infiltration in infected tissues (AlSheikhly \& Truscott, 1977b; Shane et al., 1985; Gazdzinsky \& Julian, 1992). In gas gangrene, a disease proved to be mediated by alpha toxin, marked leukostasis and lack of inflammatory infiltrate is commonly observed in the tissues infected by $C$. perfringens cells (Flores-Díaz \& Alape-Girón, 2003). Alpha toxin-negative mutants of $C$. perfringens are not able to cause gas gangrene in mice but do promote profound inflammatory responses (Awad et al., 1995). Thus, the massive immune-cell influx in necrotic enteritis lesions seems to be inconsistent with the known effects of alpha toxin on the innate immune system.

Recently, a novel toxin has been described that is associated with necrotic enteritis in broilers (Keyburn et al., 2008). The $C$. perfringens necrotic enteritis B-like toxin (NetB) is a 
member of the $\beta$-barrel pore-forming toxin family. The toxin causes cell rounding and lysis in a chicken Leghorn male hepatoma cell line (LMH), and it was shown that NetB forms plasma membrane pores with an estimated pore diameter of 1.6 - $1.8 \mathrm{~nm}$ (Keyburn et al., 2008). Lepp et al. (2010) found that the netB gene is located on an approximately $85 \mathrm{~kb}$ plasmid. The VirSR two-component signal transduction system regulates the expression of netB. The NetB toxin production is upregulated when the VirSR system is activated as a result of a high C. perfringens population density. This is an efficient environmental adaptation since NetB would only be produced when the $C$. perfringens concentration is high and there is an increased probability of subsequent nutrient limitation. Damage of the host cells caused by NetB might provide enough nutrients for C. perfringens (Cheung et al., 2010).

A netB null mutant of $C$. perfringens failed to cause necrotic lesions in the gut of experimentally infected broilers, but a mutant complemented with the wild-type netB gene was as virulent as the wild-type strain (Keyburn et al., 2008). Confirmation of the role of NetB in disease came from the finding that most necrotic enteritis outbreak strains carry the $n e t B$ gene, whereas non-necrotic enteritis derived $C$. perfringens isolates lack this gene (Keyburn et al., 2008; Keyburn et al., 2010). This gene is only found in poultry C. perfringens strains, except for one isolate that was recovered from a cow (Martin \& Smyth, 2009). Moreover, several groups screened $C$. perfringens isolates derived from different countries for the occurrence of netB. In a Canadian study, 95\% (39/41) of $C$. perfringens isolates from broilers with necrotic enteritis were positive for $n e t B$ while only $35 \%(7 / 20)$ isolates from healthy boilers were $n e t B$ positive (Chalmers et al., 2008). A screening of isolates from the US reported a carriage rate of $58 \%$ (7/12) for the necrotic enteritis isolates while only $8.75 \%$ (7/80) normal microbiota strains carried the netB gene (Martin and Smyth, 2009). Despite the fact that the netB gene is strongly associated with necrotic enteritis-derived strains, in every study a minor fraction of $n e t B$ negative isolates from diseased birds and a 
minor fraction of netB positive isolates from healthy birds are found. However, because necrotic enteritis is a multifactorial disease, the presence of netB positive strains without disease may be due to the lack of predisposing factors. The netB negative isolates from birds suffering from necrotic enteritis may indicate that other, yet to be determined virulence factors are produced by these strains. However, net $B$ negative strains do not induce necrotic enteritis in experimental animal models. To determine if $n e t B$ is essential for virulence, it is important to test the disease producing capability of both $n e t B$ positive strains recovered from healthy chickens, and netB negative strains recovered from chickens suffering from necrotic enteritis. Recent studies, using a large number of NetB positive and NetB negative C. perfringens strains to inoculate broiler chickens, showed a perfect match between necrotic enteritis induction and the ability to produce NetB (Keyburn et al., 2010; Smyth \& Martin, 2010).

Adhesion. Recently, it has been shown that $C$. perfringens is capable of binding to extracellular matrix molecules (Martin \& Smyth, 2010; Wade et al., 2010). The ability to adhere to the host's intestinal epithelium and to extracellular matrix molecules (ECMMs) in the gut are strategies used by numerous bacterial enteropathogens. Although, ECMMs are not normally exposed on healthy intestinal epithelium, they can be exposed as a consequence of tissue damage by Eimeria species, which are an important predisposing factor for necrotic enteritis development, or by toxins and collagenolytic enzymes secreted by $C$. perfringens.

It has been shown that disease producing strains bind better to collagen type III and IV and fibrinogen than non-disease producing strains. It has also been shown that netB positive severe disease producing strains were capable of binding to collagen type III, IV, and V, fibrinogen, laminin and vitronectin at higher levels than $n e t B$ positive mild disease producing 
strains. This suggests that the presence of $n e t B$, a critical factor in the development of necrotic enteritis, and the ability to adhere to ECMMs work synergistically (Martin \& Smyth, 2010).

This hypothesis is supported by the work of Wade et al. (2010): a gene, strongly associated with disease-causing isolates, was mutated in a virulent strain background and the mutant showed an altered ability to bind to immobilized ECMMs in vitro. But more importantly, the isogenic mutant strain was less able to colonize the gut environment and displayed a seriously reduced virulence in a disease induction model. The ability to adhere to ECMMs thus has a significant role in the virulence and is an important factor for colonization of the gastrointestinal tract (Wade et al., 2010).

\section{General discussion.}

After it was shown that alpha toxin is not an essential virulence factor in necrotic enteritis in broiler chickens (Keyburn et al., 2006; Timbermont et al., 2009a), new C. perfringens virulence factors have been proposed and new insight has been gained into the pathogenesis of $C$. perfringens induced necrotic enteritis. The current knowledge is summarized in Figure 2.

In short, Eimeria parasites induce leakage of plasma proteins by killing epithelial cells as a consequence of the intracellular stages of their life cycle. Moreover, according to Collier et al. (2008), a coccidial infection enhances mucus production in the intestine. Both effects provide an increase in available nutrients and create an environment favourable for proliferation of $C$. perfringens. Indeed, C. perfringens lacks the machinery to produce 13 amino acids (Shimizu et al., 2002) but is able to utilize mucus as a substrate (Collier et al., 2008). Taken together, Eimeria infection is an important predisposing factor as it may result 
in massive proliferation of $C$. perfringens in the gut. C. perfringens not only produces toxins but also bacteriocins. A significantly higher proportion of virulent C. perfringens strains produce bacteriocins compared to normal microbiota C. perfringens strains (Barbara et al., 2008; Timbermont et al., 2009b). By inhibiting other $C$. perfringens strains, the virulent strains are able to obtain the maximum benefit of the increased nutrient availability due to the Eimeria infection. The virulent strain is thus able to proliferate massively and secretes virulence factors playing a role in the induction of necrotic lesions. Olkowski et al. (2006; 2008) suggested that the nature of the morphological changes seen in the early stages of necrotic enteritis is consistent with the action of collagenolytic enzymes. Indeed, the pathological changes start at the basal and lateral domains of enterocytes and then invade progressively the entire lamina propria. Both host collagenases and collagenolytic enzymes secreted by proliferating pathogens may play a role. It has been shown that virulent C. perfringens strains are able to secrete collagenolytic enzymes and high levels of different collagenolytic enzymes are found in intestinal tissue of broilers challenged with C. perfringens, in comparison to controls (Olkowski et al., 2008). Furthermore, the NetB toxin is crucial for the induction of avian necrotic enteritis (Keyburn et al., 2008). It is, with one exception, only found in chicken $C$. perfringens isolates (Martin \& Smyth, 2009). A $100 \%$ correlation has been found between NetB production and the ability to produce disease in a necrotic enteritis induction model (Keyburn et al., 2010; Smyth \& Martin, 2010). NetB forms pores in a chicken epithelial cell line in vitro. Its activity in vivo is not yet been shown, but it may induce necrotic lesions by forming pores in enterocytes leading to cell death (Keyburn et al., 2008; Keyburn et al., 2010). Whether this is involved in the early or later stages of disease progression is not clear. Because of the damage induced by the Eimeria parasites, the $C$. perfringens toxins and the collagenolytic enzymes, virulent $C$. perfringens strains are able to bind to exposed ECMMs, to colonize the intestine and thus to induce more 
severe lesions (Martin \& Smyth, 2010; Wade et al., 2010). Not only an environment favourable for the growth of $C$. perfringens but also the presence of strains with host specific virulence factors are required to induce necrotic enteritis in broilers. 


\section{References}

Abildgaard, L., Sondergaard, T.E., Engberg, R.M., Schramm, A. \& Højberg, O. (2010). In vitro production of necrotic enteritis toxin $\mathrm{B}, \mathrm{NetB}$, by netB-positive and netB-negative Clostridium perfringens originating from healthy and diseased broiler chickens. Veterinary Microbiology, 144, 231-235.

Al-Sheikhly, F. \& Al-Saieg, A. (1980). Role of coccidia in the occurrence of necrotic enteritis of chickens. Avian Diseases, 24, 324-333.

Al-Sheikhly, F. \& Truscott, R.B. (1977a). The pathology of necrotic enteritis of chickens following infusion of broth cultures of Clostridium perfringens into the duodenum. Avian Diseases, 21, 230-240.

Al-Sheikhly, F. \& Truscott, R.B. (1977b). The pathology of necrotic enteritis of chickens following infusion of crude toxins of Clostridium perfringens into the duodenum. Avian Diseases, 21, 230-240.

Awad, M.M., Bryant, A.E., Stevens, D.L. \& Rood, J.I. (1995). Virulence studies on chromosomal alpha-toxin and theta-toxin mutants constructed by allelic exchange provide genetic evidence for the essential role of alpha-toxin in Clostridium perfringens-mediated gas gangrene. Molecular Microbiology, 15, 191-202.

Baba, E., Ikemoto, T., Fukata, T., Sasai, K., Arakawa, A. \& McDougald, L.R. (1997). Clostridial population and the intestinal lesions in chickens infected with Clostridium perfringens and Eimeria necatrix. Veterinary Microbiology, 54, 301-308.

Barbara, A.J., Trinh, H.T., Glock, R.D. \& Songer, J.G. (2008). Necrotic enteritis-producing strains of Clostridium perfringens displace non-necrotic enteritis strains from the gut of chicks. Veterinary Microbiology, 126, 377-382. 
Branton, S.L., Reece, F.N. \& Hagler, W.M. Jr. (1987). Influence of a wheat diet on mortality of broiler chickens associated with necrotic enteritis. Poultry Science, 66, 1326-1330.

Broussard, C.T., Hofacre, C.L., Page, R.K. \& Fletcher, O.J. (1986). Necrotic enteritis in cagereared commercial layer pullets. Avian Diseases, 30, 617-619.

Chalmers, G., Bruce, H.L., Hunter, D.B., Parreira, V.R., Kulkarni, R.R., Jiang, Y.-F., Prescott, J.F. \& Boerlin, P. (2008). Multilocus sequence typing analysis of Clostridium perfringens isolates from necrotic enteritis outbreaks in broiler chicken populations. Journal of Clinical Microbiology, 46, 3957-3964.

Cheung, J.K, Keyburn, A.L., Carter, G.P., Lanckriet, A.L., Van Immerseel, F., Moore, R.J. \& Rood, J.I. (2010). The VirSR two-component signal transduction system regulates NetB toxin production in Clostridium perfringens. Infection and Immunity, 78, 3064-3072.

Choct, M., Hughes, R.J., Wang, J., Bedford, M.R., Morgan, A.J. \& Annison, G. (1996). Increased small intestinal fermentation is partly responsible for the anti-nutritive activity of non-starch polysaccharides in chickens. British Poultry Science, 37, 609-621.

Collier, C.T., Hofacre, C.L., Payne, A.M., Anderson, D.B., Kaiser, P., Mackie, R.I. \& Gaskins, H.R. (2008). Coccidia-induced mucogenesis promotes the onset of necrotic enteritis by supporting Clostridium perfringens growth. Veterinary Immunology and Immunopathology, 122, 104-115.

Cowen, B.S., Schwartz, L.D., Wilson, R.A. \& Ambrus, S.I. (1987). Experimentally induced necrotic enteritis in chickens. Avian Diseases, 31, 904-906.

Craven, S.E. (2000). Colonization of the intestinal tract by Clostridium perfringens and fecal shedding in diet-stressed and unstressed broiler chickens. Poultry Science, 79, 843-849.

Dahiya, J.P., Wilkie, D.C., Van Kessel, A.G. \& Drew, M.D. (2006). Potential strategies for controlling necrotic enteritis in broiler chickens in post-antibiotic era. Animal Feed Science and Technology, 129, 60-88. 
Drew, M.D., Syed, N.A., Goldade, B.G., Laarveld, B. \& Van Kessel, A.G. (2004). Effects of dietary protein source and level on intestinal populations of Clostridium perfringens in broiler chickens. Poultry Science, 83, 414-420.

Elwinger, K., Schneitz, C., Berndtson, E., Fossum, O, Teglöf, B. \& Engström, B. (1992). Factors affecting the incidence of necrotic enteritis, caecal carriage of Clostridium perfringens and bird performance in broiler chicks. Acta Veterinaria Scandinavica, 33, 369-378.

Engberg, R.M., Hedemann, M.S. \& Jensen, B.B. (2002). The influence of grinding and pelleting of feed on the microbial composition and activity in the digestive tract of broiler chickens. British Poultry Science, 43, 569-579.

Engström, B.E., Fermér, C., Lindberg, A., Saarinen, E., Båverud, V. \& Gunnarson, A. (2003). Molecular typing of isolates of Clostridium perfringens from healthy and diseased poultry. Veterinary Microbiology, 94, 225-235.

Flores-Díaz, M. \& Alape-Girón, A. (2003). Role of Clostridium perfringens phospholipase C in the pathogenesis of gas gangrene. Toxicon, 15, 979-986.

Gazdzinski, P. \& Julian, R.J. (1992). Necrotic enteritis in turkeys. Avian Diseases, 36, 792798.

Gholamiandehkordi, A.R., Ducatelle, R., Heyndrickx, M., Haesebrouck, F. \& Van Immerseel, F. (2006). Molecular and phenotypical characterization of Clostridium perfringens isolates from poultry flocks with different disease status. Veterinary Microbiology, 113, 143-152.

Gholamiandehkordi, A.R., Timbermont, L., Lanckriet, A., Van Den Broeck, W., Pedersen, K., Dewulf, J., Pasmans, F., Haesebrouck, F., Ducatelle, R. \& Van Immerseel, F. (2007). Quantification of gut lesions in a subclinical necrotic enteritis model. Avian Pathology, 36, 375-382. 
Helmboldt, C.F. \& Bryant, E.S. (1971). The pathology of necrotic enteritis in domestic fowl. Avian Diseases, 15, 775-780.

Hofshagen, M. \& Kaldhusdal, M. (1992). Barley inclusion and avoparcin supplementation in broiler diets. 1. Effect on small intestinal bacterial flora and performance. Poultry Science, 71, 959-969.

Jack, R.W., Tagg, J.R. \& Ray, B. (1995). Bacteriocins of Gram-positive bacteria. Microbiological Reviews, 59, 171-200.

Jia ,W., Slominski, B.A., Bruce, H.L., Blank, G., Crow, G. \& Jones, O. (2009). Effect of diet type and enzyme addition on growth-performance and gut health of broiler chickens during subclinical Clostridium perfringens challenge. Poultry Science, 88, 132-140.

Kaldhusdal, M. \& Hofshagen, M. (1992). Barley inclusion and avoparcin supplementation in broiler diets. 2. Clinical, pathological, and bacteriological findings in a mild form of necrotic enteritis. Poultry Science, 71, 1145-1153.

Kaldhusdal, M. \& Skjerve, E. (1996). Association between cereal contents in the diet and incidence of necrotic enteritis in broiler chickens in Norway. Preventive Veterinary Medicine, 28, 1-16.

Kaldhusdal, M., Hofshagen, M., Løvland, A., Langstrand, H. \& Redhead, K. (1999). Necrotic enteritis challenge models with broiler chickens raised on litter: evaluation of preconditions, Clostridium perfringens strains and outcome variables. FEMS Immunology and Medical Microbiology, 24, 337-343.

Kaldhusdal, M., Schneitz, C., Hofshagen, M. \& Skjerve, E. (2001). Reduced incidence of Clostridium perfringens-associated lesions and improved performance in broiler chickens treated with normal intestinal bacteria from adult fowl. Avian Diseases, 45, 149-156. 
Keyburn, A.L., Boyce, J.D., Vaz, P., Bannam, T.L., Ford, M.E., Parker, D., Di Rubbo, A., Rood, J.I. \& Moore, R.J. (2008). NetB, a new toxin that is associated with avian necrotic enteritis caused by Clostridium perfringens. PLoS Pathogens, 4, e26.

Keyburn, A.L., Sheedy, S.A., Ford, M.E., Williamson, M.M., Awad, M.M., Rood, J.I. \& Moore, R.J. (2006). Alpha-toxin of Clostridium perfringens is not an essential virulence factor in necrotic enteritis in chickens. Infection and Immunity, 74, 6496-6500.

Keyburn, A.L., Yan, X.-X., Bannam, T.L., Van Immerseel, F., Rood, J.I. \& Moore, R.J. (2010). Association between avian necrotic enteritis and Clostridium perfringens strains expressing NetB toxin. Veterinary Research, 41, 21.

Knarreborg, A., Simon, M.A., Engberg, R.M., Jensen, B.B. \& Tannock, G.W. (2002). Effects of dietary fat source and subtherapeutic levels of antibiotic on the bacterial community in the ileum of broiler chickens at various ages. Applied and Environmental Microbiology, $68,5918-5924$.

Köhler, B. (1973). Diseases in man and animal caused by Clostridium perfringens and their relations. Zeitschrift fur Die Gesamte Hygiene und Ihre Grenzgebiete, 19, 228-234.

Lepp, D., Roxas, B., Parreira, V.R., Marri, P.R., Rosey, E.L., Gong, J., Songer, J.G., Vedantam, G. \& Prescott, J.F. (2010). Identification of novel pathogenicity loci in Clostridium perfringens strains that cause avian necrotic enteritis. PLoS ONE, 5, e10795.

Long, J.R. \& Truscott, R.B. (1976). Necrotic enteritis in broiler chickens. III. Reproduction of the disease. Canadian Journal of Comparative Medicine, 40, 53-59.

Long, J.R. (1973). Necrotic enteritis in broiler chickens. I. A review of the literature and the prevalence of the disease in Ontario. Canadian Journal of Comparative Medicine, 37, 302308. 
Long, J.R., Pettit, J.R. \& Barnum, D.A. (1974). Necrotic enteritis in broiler chickens. II. Pathology and proposed pathogenesis. Canadian Journal of Comparative Medicine, 38, 467-474.

Løvland, A. \& Kaldhusdal, M. (1999). Liver lesions seen at slaughter as an indicator of necrotic enteritis in broiler flocks. FEMS Immunology and Medical Microbiology, 24, 345351.

Martin, T.G. \& Smyth, J.A. (2009). Prevalence of $n e t B$ among some clinical isolates of Clostridium perfringens from animals in the United States. Veterinary Microbiology, 136, 202-205.

Martin, T.G. \& Smyth, J.A. (2010). The ability of disease and non-disease producing strains of Clostridium perfringens from chickens to adhere to extracellular matrix molecules and Caco-2 cells. Anaerobe, 16, 533-539.

McDevitt, R.M., Brooker, J.D., Acamovic, T. \& Sparks, N.H.C. (2006). Necrotic enteritis; a continuing challenge for the poultry industry. World's Poultry Science Journal, 62, 221247.

Myers, G.S.A., Rasko, D.A., Cheung, J.K., Ravel, J., Seshadri, R., DeBoy, R.T., Ren, Q., Varga, J., Awad, M.M., Brinkac, L.M., Daugherty, S.C., Haft, D.H., Dodson, R.J., Madupu, R., Nelson, W.C., Rosovitz, M.J., Sullivan, S.A., Khouri, H., Dimitrov, G.I., Watkins, K.L., Mulligan, S., Benton, J., Radune, D., Fisher, D.J., Atkins, H.S., Hiscox, T., Jost, B.H., Billington, S.J., Songer, J.G., McClane, B.A., Titball, R.W., Rood, J.I., Melville, S.B. \& Paulsen, I.T. (2006). Skewed genomic variability in strains of the toxigenic bacterial pathogen, Clostridium perfringens. Genome Research, 16, 1031-1040.

Nauerby, B., Pedersen, K. \& Madsen, M. (2003). Analysis by pulsed-field gel electrophoresis of the genetic diversity among Clostridium perfringens isolates from chickens. Veterinary Microbiology, 94, 257-266. 
Olkowski, A.A., Wojnarowicz, C., Chinio-Trejo, M. \& Drew, M.D. (2006). Responses of broiler chickens orally challenged with Clostridium perfringens isolated from field cases of necrotic enteritis. Research in Veterinary Science, 81, 99-108.

Olkowski, A.A., Wojnarowicz, C., Chirino-Trejo, M., Laarveld, B. \& Sawicki, G. (2008). Sub-clinical necrotic enteritis in broiler chickens: novel etiological consideration based on ultra-structural and molecular changes in the intestinal tissue. Research in Veterinary Science, 85, 543-553.

Onderka, D.K., Langevin, C.C. \& Hanson, J.A. (1990). Fibrosing cholehepatitis in broiler chickens induced by bile duct ligations or inoculation of Clostridium perfringens. Canadian Journal of Veterinary Research, 54, 285-290.

Parish, W.E. (1961). Necrotic enteritis in fowl (Gallus Gallus domesticus). 1. Histopathology of the disease and isolation of a strain of Clostridium welchii. Journal of Comparative Pathology, 71, 337-393.

Park, S.S., Lillehoj, H.S., Allen, P.C., Park, D.W., FitzCoy, S., Baurista, D.A. \& Lillehoj, E.P. (2008). Immunopathology and cytokine responses in broiler chickens coinfected with Eimeria maxima and Clostridium perfringens with the use of an animal model of necrotic enteritis. Avian Diseases, 52, 14-22.

Pedersen, K., Bjerrum, L., Heuer, O.E., Lo Fo Wong, D.M. \& Nauerby, B. (2008). Reproducible infection model for Clostridium perfringens in broiler chickens. Avian Diseases, 52, 34-39.

Pedersen, K., Bjerrum, L., Nauerby, B. \& Madsen, M. (2003). Experimental infections with rifampicin-resistant Clostridium perfringens strains in broiler chickens using isolator facilities. Avian Pathology, 32, 403-411.

Porter, R.E. Jr. (1998). Bacterial enteritides of poultry. Poultry Science, 77, 1159-1165. 
Riddell, C. \& Kong, X.M. (1992). The influence of diet on necrotic enteritis in broiler chickens. Avian Diseases, 36, 499-503.

Sasaki, J., Goryo, M., Okoshi, N., Furukawa, H., Honda, J. \& Okada, K. (2000).

Cholangiohepatitis in broiler chickens in Japan: histopathological, immunohistochemical and microbiological studies of spontaneous disease. Acta Veterinaria Hungarica, 48, 5967.

Shane, S.M., Gyimah, J.E., Harrington, K.S. \& Snider, T.G. $3^{\text {rd }}$ (1985). Etiology and pathogenesis of necrotic enteritis. Veterinary Research Communications, 9, 269-287.

Shimizu, T., Ohtani, K., Hirakawa, H., Ohshima, K., Yamashita, A., Shiba, T., Ogasawara, N., Hattori, M., Kuhara, S. \& Hayashi, H. (2002). Complete genome sequence of Clostridium perfringens, an anaerobic flesh-eater. Proceedings of the National Academy of Sciences of the United States of America, 99, 996-1001.

Si, W., Gong, J., Han, Y., Yu, H., Brennan, J., Zhou, H. \& Chen, S. (2007). Quantification of cell proliferation and alpha-toxin gene expression of Clostridium perfringens in the development of necrotic enteritis in broiler chickens. Applied and Environmental Microbiology, 73, 7110-7113.

Smyth, J.A. \& Martin, T.G. (2010). Disease producing capability of netB positive isolates of C. perfringens recovered from normal chickens and a cow, and netB positive and negative isolates from chickens with necrotic enteritis. Veterinary Microbiology, 146, 76-84.

Timbermont, L., Lanckriet, A., Gholamiandehkordi, A.R., Pasmans, F., Martel, A., Haesebrouck, F., Ducatelle, R. \& Van Immerseel, F. (2009a). Origin of Clostridium perfringens isolates determines the ability to induce necrotic enteritis in broilers. Comparative Immunology, Microbiology and Infectious Diseases, 32, 503-512.

Timbermont, L., Lanckriet, A., Pasmans, F., Haesebrouck, F., Ducatelle, R. \& Van Immerseel, F. (2009b). Intra-species growth-inhibition by Clostridium perfringens is a 
possible virulence trait in necrotic enteritis in broilers. Veterinary Microbiology, 137, 388391.

Truscott, R.B. \& Al-Sheikhly, F. (1977). Reproduction and treatment of necrotic enteritis in broilers. American Journal of Veterinary Research, 38, 857-861.

Van der Sluis, W. (2000a). Clostridial enteritis - a syndrome emerging world wide. World Poultry, 16, 56-57.

Van der Sluis, W. (2000b). Clostridial enteritis is an often underestimated problem. World Poultry, 16, 42-43.

Van Immerseel, F., De Buck, J., Pasmans, F., Huyghebaert, G., Haesebrouck, F. \& Ducatelle, R. (2004). Clostridium perfringens in poultry: an emerging threat of animal and public health. Avian Pathology, 33, 537-549.

Van Immerseel, F., Rood, J.I., Moore, R.J. \& Titball, R.W. (2009). Rethinking our understanding of the pathogenesis of necrotic enteritis in broilers. Trends in Microbiology, $17,32-36$.

Wade, B., Keyburn, A.L., Ford, M.E., Rood, J.I. \& Moore, R.J. (2010). Clostridium perfringens genes with implications for both virulence and colonization during necrotic enteritis. Prato Conference on the Pathogenesis of Bacterial Diseases of Animals, Prato, Italy, 72.

Wijewanta, E.A. \& Senevirtna, P. (1971). Bacteriological studies of fatal Clostridium perfringens type-A infection in chickens. Avian Diseases, 14, 654-661.

Wilkie, D.C., Van Kessel, A.G., Dumonceaux, T.J. \& Drew, M.D. (2006). The effect of henegg antibodies on Clostridium perfringens colonization of the gastrointestinal tract of broiler chickens. Preventive Veterinary Medicine, 74, 279-292. 
Williams, R.B. (2005). Intercurrent coccidiosis and necrotic enteritis of chickens: rational, integrated disease management by maintenance of gut integrity. Avian Pathology, 34, 159180. 


\section{Figures}

Figure 1. A. Confluent necrosis of the jejunum. B. Focal necrosis of the jejunum.

Figure 2. Summary of the pathogenesis of $\mathrm{C}$. perfringens induced necrotic enteritis.

In short, Eimeria parasites induce leakage of plasma proteins by killing epithelial cells (A) and enhance mucus production in the intestine $(B)$. Both effects provide an increase in available nutrients and create an environment favorable for proliferation of $\mathrm{C}$. perfringens. By producing bacteriocins and thus inhibiting other C. perfringens strains, the virulent strain is able to obtain the maximum benefit of the increased nutrient availability due to the Eimeria infection $(C)$. The pathological changes in necrotic enteritis start at the basal and lateral domains of enterocytes and then extend progressively in the entire lamina propria. Both host collagenases and collagenolytic enzymes secreted by proliferating pathogens may play a role (D). NetB may induce necrotic lesions by forming pores in enterocytes leading to cell death (E). C. perfringens binds to the ECMMs that leak into the lumen as a consequence of the lesions $(F)$. 


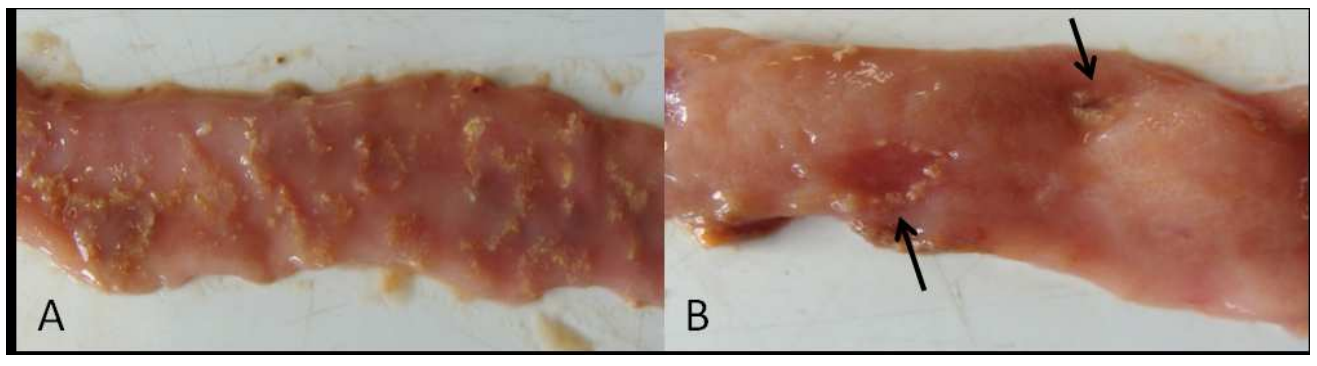

$171 \times 45 \mathrm{~mm}(150 \times 150 \mathrm{DPI})$ 


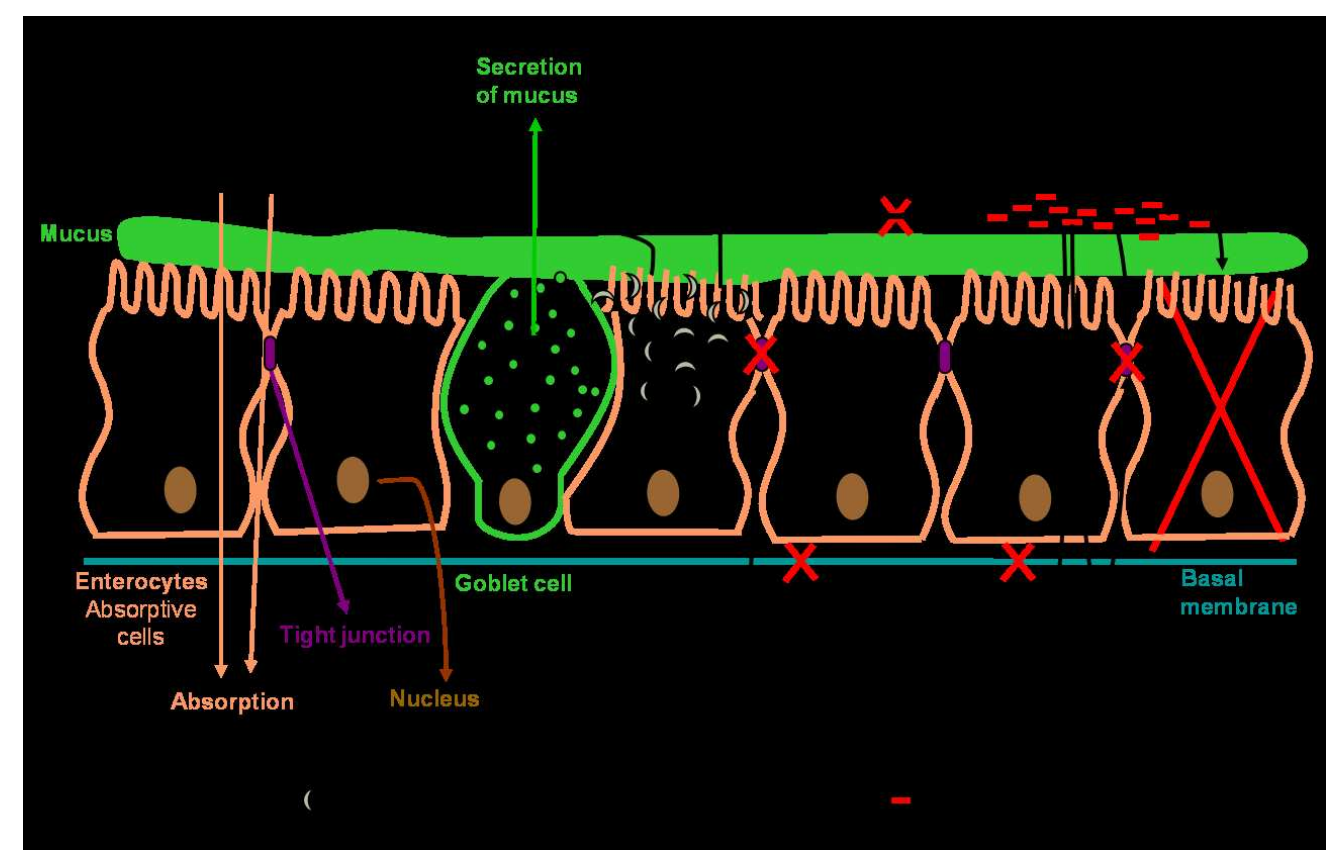

$218 \times 139 \mathrm{~mm}(150 \times 150 \mathrm{DPI})$ 